Report

\title{
BAG-1 expression correlates with Bcl-2, p53, differentiation, estrogen and progesterone receptors in invasive breast carcinoma
}

\author{
Shou-Ching Tang ${ }^{1}$, Jessalyn Beck ${ }^{2}$, Sean Murphy ${ }^{3}$, Garry Chernenko ${ }^{3}$, Desmond Robb ${ }^{3}$, \\ Peter Watson ${ }^{4}$, and Mahmoud Khalifa ${ }^{5}$ \\ ${ }^{1}$ Sylvester Comprehensive Cancer Center, University of Miami, Miami, FL, USA; ${ }^{2}$ Department of Pathology, \\ McGill University, Montreal, QC; ${ }^{3}$ Basic Medical Sciences, Memorial University of Newfoundland, St. \\ John's, NF; ${ }^{4}$ Department of Pathology, Faculty of Medicine, University of Manitoba, Winnipeg, MB; \\ ${ }^{5}$ Department of Laboratory Medicine and Pathology, Faculty of Medicine, University of Toronto, Toronto, ON, \\ Canada
}

Key words: BAG-1, Bcl-2, breast cancer, p53, prognostic factors

\begin{abstract}
Summary
BAG-1, a recently identified anti-apoptotic protein, is overexpressed in the majority of invasive breast carcinomas. Overexpression of BAG-1 is important for both multi-step oncogenesis and resistance of cancer cells to apoptosis induced by DNA-damaging alkylating agents. BAG-1 protein species are localized differentially; nuclear expression may be associated with a shorter disease-free and overall survival in early stage breast cancer, while cytoplasmic expression has been associated with longer survival in non-small cell lung cancer. Growing evidence suggests that Bcl-2 and p53 are also involved in the oncogenesis of breast cancer. Since BAG-1 interacts with Bcl-2 and is upregulated by mutant p53 in vitro, it would be interesting to determine if their expressions are correlated with each other and with other clinical prognostic factors in invasive breast cancer. To address this question we conducted a large scale retrospective study of BAG-1, Bcl-2 and p53 in 185 breast cancer patients. Our study again showed that BAG-1 is overexpressed in the majority of breast cancer patients. In addition, it demonstrated that the expression of BAG-1 correlates with that of Bcl-2, p53, differentiation, estrogen and progesterone receptors. Our clinical study supports the preclinical finding of the interaction between BAG-1 and Bcl-2, p53 and estrogen and progesterone receptors. Further experiments to explore the prognostic and therapeutic role of BAG-1 in breast cancer are warranted.
\end{abstract}

\section{Introduction}

BAG-1 is a multifunctional anti-apoptotic protein. It exists as four protein isoforms designated p50, p46, p33 and p29, which bind to proteins from four different subcellular compartments: cytosolic domains of tyrosine kinase hepatocyte growth factor (HGF) receptor and platelet derived growth factor (PDGF) receptor on outer cell membranes to increase the protection from apoptosis by HGF and PDGF, respectively [1], Bcl-2 on inner cell membranes to enhance the inhibition of apoptosis [2], cytosolic heat shock protein (hsps) to inhibit the Hsp70-mediated refolding of denatured proteins, and protect cells from heat shockinduced apoptosis [3, 4] and RAF-1 [5] and nuclear hormone receptors such as glucocorticoid, androgen, estrogen and thyroid receptors to modulate their functions [6]. Growing evidence shows that BAG-1 is overexpressed in many human cancers and that its expression may serve as prognostic and/or predictive tumor marker, as recently reviewed [7].

Differential expression of BAG-1 was also recently reported in breast, prostate, colon and leukemia cell lines $[8,9]$. Distinct isoforms of BAG-1 were noted to affect Hsp70 chaperone function differently [10]. We recently reported that forced overexpression of 
BAG-1 alone lead to decreased sensitivity to apoptosis induced by chemotherapy agents. In addition, different BAG-1 isoforms displayed differing ability to inhibit apoptosis in cervical cancer cells [11]. Taken together, these data suggest that the cytoplasmic and nuclear BAG-1 protein play a differential role in apoptosis and oncogenesis of human cancers, including breast cancer.

Breast cancer is the most common malignancy affecting women. Recently the value of proteins involved in apoptosis as prognostic factors in breast cancer treatment has been recognized. Increased expression of $\mathrm{p} 53$, a pro-apoptotic tumor suppressor gene, was associated with resistance to chemotherapy or radiation therapy, shorter disease-free and overall survival [12-14]. Increased expression of the antiapoptotic protein, Bcl-2, was found in the majority of breast cancer. Its expression was correlated with the presence of estrogen and progesterone receptors, well differentiated tumor, and was inversely correlated with p53 expression and the apoptotic index [15]. Furthermore, the expression of Bcl-2 was associated with the absence of lymph node metastases, better response to hormonal therapy, and longer disease-free and overall survival in breast cancer patients [16-19]. However, many conflicting reports demonstrate that increased expression of $\mathrm{Bcl}-2$ may not always predict a favorable clinical outcome [20-22]. In addition, the expression of $\mathrm{Bcl}-\mathrm{X}_{\mathrm{L}}$, a Bcl-2-related anti-apoptotic protein, is associated with decreased overall survival in breast cancer patients [23]. Furthermore, reduced expression of Bax, the pro-apoptotic Bcl-2 analogue, is associated with poor response to combination chemotherapy and shorter survival in patients with invasive breast cancer [24]. Even though, these data strongly suggest that apoptosis plays an important role in pathogenesis and progression of breast cancer, the use of apoptosis molecules as independent prognostic factors in breast cancer patients is still controversial $[25,26]$.

Both BAG-1 RNA and protein were overexpressed in human breast cancer cell lines and breast cancer tissues [27]. Forced expression of BAG-1 isoforms in human breast cancer cells resulted in enhanced survival during growth factor deprivation and accelerated growth in vivo [28]. These experiments strongly suggest that BAG-1 may be a reliable molecular marker for the pathogenesis and the progression of breast cancer, and that BAG-1 may serve as an independent prognostic factor in the management of breast cancer [29-33]. Since BAG-1 interacts with Bcl-2 and is upregulated by mutant $\mathrm{p} 53$, it would be interesting to study the coexpression of these pro- and anti-apoptotic proteins in invasive breast carcinoma. The correlation between the expression of BAG-1 and p53 in breast carcinoma is currently unknown. BAG-1 and Bcl-2 were both induced by treatment with IL-2 in T lymphocyte [34]. In addition, Bcl-2 and BAG-1 protein levels were positively correlated in breast cancer cell lines [35] and in breast carcinoma [31, 33], although opposite observation was made by another group [9]. Similarly, conflicting reports exist in literature on the correlation between the expression of BAG-1 and estrogen and progesterone receptors. Although BAG-1 expression was found to correlate with that of estrogen receptor in breast cancer cell lines and tissues [9], retrospective clinical studies failed to show such a correlation [31, 32]. To study the correlation of apoptosis molecules and estrogen and progesterone receptors in breast cancer patients, we conducted retrospective study using 185 paraffin-embedded breast tumor tissues. The overall expression, pattern and intensity of these proteins were correlated with conventional prognostic factors such as age, stage, histology and differentiation in order to further explore the role of BAG-1 in the pathogenesis and prognosis of breast cancer.

\section{Methods and materials}

\section{Immunohistochemistry}

All breast tumor cases used for this study were selected from the Manitoba Breast Tumor Bank (Winnipeg, Manitoba, Canada), which operates with the approval from the Faculty of Medicine, University of Manitoba, Research Ethics Board. The Tumor Bank was established in 1993. These issues are accrued to the Bank from cases at multiple centers within Manitoba, rapidly collected and processed to create matched formalin-fixed-paraffin-embedded and frozen tissue blocks with the mirror image surfaces oriented by colored inks [36, 37]. Any patients with confirmed pathological diagnosis of breast cancer and with the available tissues were included in the tissue bank collection. We selected 185 samples from the tissue bank that had the matching clinical data such as age, stage and treatment, and the complete pathological diagnosis such as ER and PR. Patients with second primary cancer, and those with incomplete clinical and pathological information were excluded from the study. The histology and cellular compo- 
sition of every sample in the Bank is interpreted in hematoxylin and eosin (H\&E) stained sections from the face of the former tissue block. Immunohistochemical staining for ER and PR was performed on entry into the tissue bank [36]. For both estrogen and progesterone receptor analyses, a negative staining was considered to be that of 3.5 or less stained nuclei per high-powered field, equivocal was considered 3.6-20.4 nuclei, and positive was 20.5 or more nuclei. Deparaffinization was carried out in xylene. The slides were then re-hydrated in a decreasing ethanol series ending in distilled water. Endogenous peroxidase activity was quenched using $0.6 \%$ hydrogen peroxide in $100 \%$ methanol for $15 \mathrm{~min}$. Slides were placed in a humid chamber and incubated at room temperature for $60 \mathrm{~min}$ with $10 \%$ normal goat serum (D3002S, Dimension Laboratories) in phosphate buffered saline (PBS) containing $0.1 \%$ Triton X-100 (X-100, Sigma) to block non-specific staining. Sections were incubated at room temperature for $1 \mathrm{~h}$ with diluted primary antibody: BAG-1 rabbit polyclonal (C-16, Santa Cruz Biotechnology) at $250 \times$ dilution; Bcl-2 mouse anti-human (OP60, Calbiochem) at 25x dilution, p53 mouse anti-human (OP09, Calbiochem) at $40 \times$ dilution. Staining pattern was not studied for p53 because all staining is nuclear.

The immunohistochemistry for BAG-1 was performed as previously described [29, 38]. The sections were then incubated for $1 \mathrm{~h}$ with a $200 \times$ dilution of biotinylated goat anti-rabbit IgG (BA-1000, Vector Laboratories) for BAG-1 detection, and with a $200 \times$ dilution of biotinylated goat anti-mouse IgG (62-6540, Zymed) for Bcl-2 and p53 detection. Slides were rinsed thoroughly with PBS between each of the above steps. Sections were then exposed to a diaminobenzadine (D-5673, Sigma) peroxidase substrate solution (DAB) for $5 \mathrm{~min}$. The reaction was stopped using distilled water. Sections were then dehydrated in an increasing ethanol series and xylene, then covered slipped using Permount (SP153-100, Fisher Scientific). Normal breast tissue surrounding the tumor portion of the slides was used as internal negative control for immunohistochemistry. Slides from breast cancer and lung cancer, positive for BAG1 expression from our previous studies, were used as positive controls [29, 38]. All slides were examined by two observers (including an independent pathologist) and categorized according to the subcellular location of staining (nucleus v.s. cytoplasmic) and the intensity (zero or no staining, light and intense staining); the concordance between the two blinded observers was close to $100 \%$. Diagnosis of breast cancer, tumor grade and ER/PR status was made by a pathologist not involved with the study and was confirmed by independent pathologists involved with the study. The observers reviewing the stained slides were blinded to the clinical information of the corresponding patients. Three slides from each tumor sample were stained. The percentage of positively stained cells within any tumor sample varied from section to section, and the slide with the highest percentage of positively stained cells (at least over 25\%) was chosen to score for BAG-1 expression.

\section{Statistical analysis}

Statistical analysis was performed using SPSS version 7.5.1 for Windows 95 (SPSS Inc., Chicago, IL) as previously described [29]. Spearman rho correlation coefficient and logistic regression by univariate and multivariate analysis were used to determine the significance of the association of the different factors. Expression is defined as negative or positive staining, staining pattern is defined as nuclear or cytoplasmic staining, and staining intensity is either faint or strong. The level of significance for all analyses was set at 0.05 . Assuming an overall survival of invasive breast cancer at 10 years is $60 \%$, a sample size of 185 would have a $90 \%$ power to detect at least $20 \%$ difference in survival, with a significance level of $5 \%$, based one one-sided test.

\section{Results}

\section{Patient population}

One-hundred-eighty-five patients were included in this study. The age distribution, pathological diagnosis such as differentiation, histology, ER and PR status and the clinical data such as stage and treatment modalities are summarized in Table 1. At the time of analysis, 107 patients $(\sim 58.0 \%)$ were alive with no recurrence, 9 patients $(\sim 5.0 \%)$ were recurrence-free and deceased due to other causes, 40 patients $(\sim 21.5 \%)$ experienced recurrence and died due to breast cancer, 23 patients $(\sim 12.0 \%)$ experienced recurrence and were alive, 1 patient $(0.5 \%)$ experienced recurrence and died due to other causes, and 5 patients $(\sim 3.0 \%)$ were deceased due to unknown causes. The median follow-up of the patient population was 44.0 months (38.0-60.0). 
Table 1. Summarized patient data

\begin{tabular}{|c|c|c|}
\hline Characteristics & Number & $\%$ \\
\hline Number of patients & 185 & \\
\hline \multicolumn{3}{|l|}{ Age of diagnosis (years) } \\
\hline Range & $31-93$ & \\
\hline Mean & 60.37 & \\
\hline Median & 61 & \\
\hline \multicolumn{3}{|l|}{ Differentiation } \\
\hline Well & 0 & 0.0 \\
\hline Moderate & 72 & 39.0 \\
\hline Poor & 108 & 58.0 \\
\hline Missing info. & 5 & 3.0 \\
\hline \multicolumn{3}{|l|}{ Histology } \\
\hline Invasive ductal & 142 & 77.0 \\
\hline Invasive lobular & 24 & 13.0 \\
\hline Invasive ductal/lobular mixed & 16 & 8.5 \\
\hline Missing info. & 3 & 1.5 \\
\hline \multicolumn{3}{|l|}{ Stage } \\
\hline I & 27 & 14.6 \\
\hline II & 106 & 57.3 \\
\hline III & 13 & 7.0 \\
\hline IV & 11 & 6.0 \\
\hline Missing info. & 28 & 15.1 \\
\hline \multicolumn{3}{|l|}{ Estrogen receptors } \\
\hline Negative & 48 & 26.0 \\
\hline Equivocal & 56 & 30.0 \\
\hline Positive & 81 & 44.0 \\
\hline \multicolumn{3}{|l|}{ Progesterone receptors } \\
\hline Negative & 14 & 7.0 \\
\hline Equivocal & 92 & 50.0 \\
\hline Positive & 79 & 43.0 \\
\hline \multicolumn{3}{|l|}{ Treatments } \\
\hline Hormone & 67 & 36.0 \\
\hline Chemotherapy & 15 & 8.0 \\
\hline Radiation & 6 & 3.0 \\
\hline Hormone/CT & 9 & 5.0 \\
\hline Hormone/RT & 28 & 15.0 \\
\hline CT/RT & 14 & 8.0 \\
\hline Hormone/CT/RT & 9 & 5.0 \\
\hline None of the above & 37 & 20.0 \\
\hline
\end{tabular}

CT, Chemotherapy, RT, Radiation, CT/RT, Chemotherapy and Radiation.

\section{$B A G-1$ staining}

Of the 184 tumor sections that were stained for BAG-1, $25(\sim 13.5 \%)$ had negative staining and $159(\sim 86.0 \%)$ had positive staining. One-hundred-
Table 2. Expression of p53, Bcl-2 and BAG-1

\begin{tabular}{|c|c|c|}
\hline Factor & Number & $\%$ \\
\hline \multicolumn{3}{|l|}{ p53 expression } \\
\hline Negative & 135 & 73.0 \\
\hline Positive & 43 & 23.0 \\
\hline Missing info. & 7 & 4.0 \\
\hline \multicolumn{3}{|l|}{ p53 intensity } \\
\hline Negative & 135 & 73.0 \\
\hline Faint & 22 & 12.0 \\
\hline Strong & 21 & 11.0 \\
\hline Missing info. & 7 & 4.0 \\
\hline \multicolumn{3}{|l|}{ Bcl-2 expression } \\
\hline Negative & 13 & 7.0 \\
\hline Positive & 172 & 93.0 \\
\hline \multicolumn{3}{|l|}{ Bcl-2 patttern } \\
\hline Negative & 13 & 7.0 \\
\hline Cytoplasmic & 129 & 70.0 \\
\hline Nuclear & 43 & 23.0 \\
\hline \multicolumn{3}{|l|}{ Bcl-2 intensity } \\
\hline Negative & 13 & 7.0 \\
\hline Faint & 123 & 66.5 \\
\hline Strong & 49 & 26.5 \\
\hline \multicolumn{3}{|c|}{ BAG-1 expression } \\
\hline Negative & 25 & 13.5 \\
\hline Positive & 159 & 86.0 \\
\hline Missing info. & 1 & 0.5 \\
\hline \multicolumn{3}{|l|}{ BAG-1 pattern } \\
\hline Negative & 25 & 13.5 \\
\hline Cytoplasmic & 158 & 85.5 \\
\hline Nuclear & 1 & 0.5 \\
\hline Missing info. & 1 & 0.5 \\
\hline \multicolumn{3}{|l|}{ BAG-1 intensity } \\
\hline Negative & 25 & 13.5 \\
\hline Faint & 113 & 61.0 \\
\hline Strong & 46 & 25.0 \\
\hline Missing info. & 1 & 0.5 \\
\hline
\end{tabular}

fifty-nine $(\sim 85.5 \%)$ of the positive cases were cytoplasmic, $1 \quad(\sim 0.5 \%)$ was nuclear, $113(\sim 61.0 \%)$ had faint staining and $46(\sim 25.0 \%)$ had strong staining, as summarized in Table 2. Figure 1(a) and (b) shows representative sections for strong cytoplasmic and weak nuclear BAG-1 staining, respectively.

Spearman rho analysis pairing and comparing BAG-1 expression, pattern, and intensity to $\mathrm{Bcl}-2$ and 

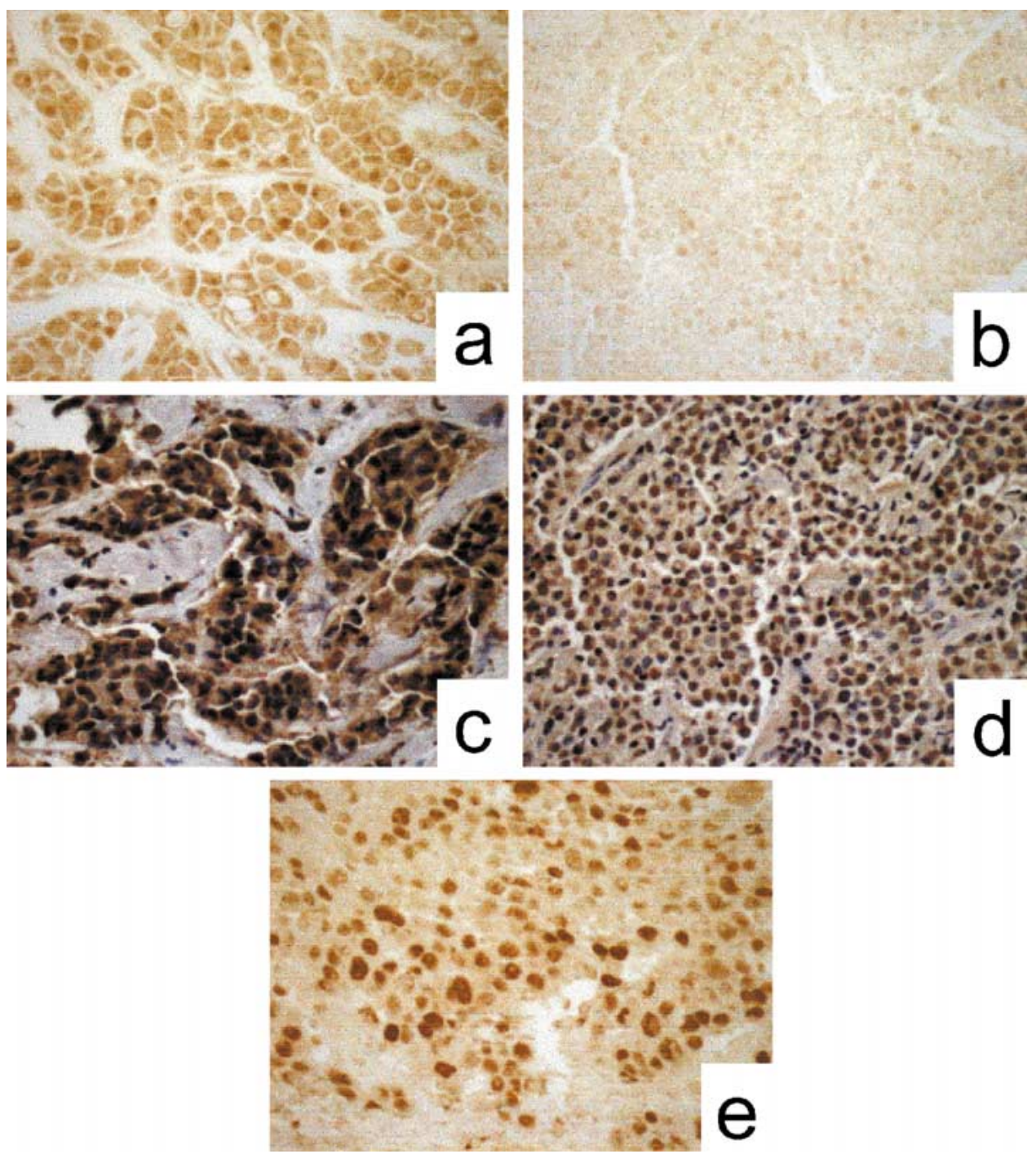

Figure 1. (a) Strong cytoplasmic BAG-1 staining in breast tumor. (b) Weak nuclear BAG-1 staining in breast tumor. (c) Strong cytoplasmic Bcl-2 staining in breast tumor; counterstained with hematoxylin. (d) Weak nuclear Bcl-2 staining in breast tumor; counterstained with hematoxylin. (e) Strong nuclear p53 staining in breast tumor.

p53 expression, pattern, and intensity, age, differentiation, stage, estrogen and progesterone receptors is summarized in Table 3 . The expression of BAG-1 correlated with that of $\mathrm{Bcl}-2$ expression pattern $(-0.173)$, p53 expression $(-0.245)$ and intensity $(-0.270)$, differentiation $(-0.222)$, estrogen $(0.285)$ and progesterone $(0.182)$ receptors. BAG-1 pattern correlated with that of Bcl-2 expression pattern $(-0.174)$, p53 expression (0.247) and intensity $(-0.271)$, estrogen $(0.292)$ and progesterone $(0.193)$ receptors. Only 1 of the 184 of BAG-1 staining pattern was nuclear. BAG1 intensity correlated with that of Bcl-2 expression intensity $(0.163), \mathrm{p} 53$ expression $(-0.177)$ and intens- ity $(-0.195)$, differentiation $(-0.257)$, and estrogen receptor (0.331), as summarized in Table 3(a).

Further univariate analysis by logistic regression demonstrated that the expression of BAG-1 correlated with that of $\mathrm{Bcl}-2$ expression (rate ratio $(\mathrm{RR})=3.17$, confidence interval $(\mathrm{CI})=0.90-11.23$, $p=0.07), \mathrm{Bcl}-2$ pattern $(\mathrm{RR}=6.71, \mathrm{CI}=1.694-$ 26.26, $p=0.007)$ and Bcl-2 intensity $(\mathrm{RR}=6.812$, $\mathrm{CI}=1.297-35.77, p=0.023), \mathrm{p} 53(\mathrm{RR}=2.44, \mathrm{CI}=$ $0.10-6.00, \quad p=0.002)$, differentiation $(\mathrm{RR}=5.62$, $\mathrm{CI}=1.60-19.60, p=0.0068), \mathrm{ER}(\mathrm{RR}=9.94, \mathrm{CI}=$ 2.66-37.15, $p=0.001)$ and $\mathrm{PR} \quad(\mathrm{RR}=4.035$, $\mathrm{CI}=0.84-19.3, \quad p=0.081)$, but not that of age 
Table 3. Correlation (Spearman) of BAG-1, Bcl-2 and p53 with other studied prognostic factors

(a)

\begin{tabular}{lccc}
\hline Factors & $\begin{array}{c}\text { BAG-1 } \\
\text { expression }\end{array}$ & $\begin{array}{c}\text { BAG-1 } \\
\text { pattern }\end{array}$ & $\begin{array}{c}\text { BAG-1 } \\
\text { intensity }\end{array}$ \\
\hline Age & 0.102 & 0.093 & 0.071 \\
Stage & -0.014 & -0.041 & 0.019 \\
Differentiation & $-0.222^{*}$ & -0.234 & -0.257 \\
ER & $0.285^{*}$ & $0.292^{*}$ & $0.331^{*}$ \\
PR & $0.182^{*}$ & $0.193^{*}$ & 0.133 \\
Bcl-2 expression & 0.138 & 0.139 & 0.118 \\
Bcl-2 pattern & $-0.173^{*}$ & $-0.174^{*}$ & -0.156 \\
Bcl-2 intensity & 0.027 & 0.016 & $0.163^{*}$ \\
p53 expression & $-0.245^{*}$ & $0.247^{*}$ & $-0.177^{*}$ \\
p53 intensity & $-0.270^{*}$ & $-0.271^{*}$ & $-0.195^{*}$ \\
\hline
\end{tabular}

(b)

\begin{tabular}{lccc}
\hline Factors & $\begin{array}{l}\text { Bcl-2 } \\
\text { expression }\end{array}$ & $\begin{array}{l}\text { Bcl-2 } \\
\text { pattern }\end{array}$ & $\begin{array}{l}\text { Bcl-2 } \\
\text { intensity }\end{array}$ \\
\hline Age & -0.020 & -0.058 & 0.003 \\
Stage & $0.174^{*}$ & $0.171^{*}$ & 0.023 \\
Differentiation & -0.036 & $0.240^{*}$ & -0.043 \\
ER & 0.078 & $-0.194^{*}$ & 0.029 \\
PR & 0.083 & -0.054 & 0.082 \\
BAG-1 expression & 0.138 & $-0.173^{*}$ & 0.027 \\
BAG-1 pattern & 0.139 & $-0.174^{*}$ & 0.016 \\
BAG-1 intensity & 0.118 & -0.156 & $0.163^{*}$ \\
p53 expression & -0.110 & $0.188^{*}$ & -0.081 \\
p53 intensity & -0.091 & $0.168^{*}$ & -0.076 \\
\hline
\end{tabular}

(c)

\begin{tabular}{lcc}
\hline Factors & p53 expression & p53 intensity \\
\hline Age & -0.070 & -0.084 \\
Stage & 0.005 & 0.004 \\
Differentiation & $0.359^{*}$ & $0.369^{*}$ \\
ER & $-0.306^{*}$ & $-0.326^{*}$ \\
PR & $-0.149^{*}$ & $-0.171^{*}$ \\
BAG-1 expression & $-0.245^{*}$ & $-0.270^{*}$ \\
BAG-1 pattern & $0.247^{*}$ & $-0.271^{*}$ \\
BAG-1 intensity & $-0.177^{*}$ & $-0.195^{*}$ \\
Bcl-2 expression & -0.091 & -0.110 \\
Bcl-2 pattern & $0.168^{*}$ & $0.188^{*}$ \\
Bcl-2 intensity & -0.076 & -0.081 \\
\hline
\end{tabular}

$* p<0.05$.

$(\mathrm{RR}=1.02, \quad \mathrm{CI}=0.99-1.06, \quad p=0.13), \quad$ stage $\mathrm{I}$ $(\mathrm{RR}=0.003, \mathrm{CI}=0.000->100.00, p=0.756)$, stage II $\quad(\mathrm{RR}=0.001, \quad \mathrm{CI}=0.000->100.00, \quad p=0.717)$ and stage III $(\mathrm{RR}=0.001, \mathrm{CI}=0.000->100.00$, $p=0.718)$. Multivariate analysis by logistic re- gression showed that the expression of BAG-1 was associated with that of the $E R(R R=13.26$, $\mathrm{CI}=1.004-175.138, p=0.05)$, but not with that of the $\mathrm{Bcl}-2(\mathrm{RR}=2.48, \mathrm{CI}=0.38-15.96, p=0.56)$, p53 $(\mathrm{RR}=0.49, \quad \mathrm{CI}=0.16-1.54, \quad p=0.21), \quad$ age $(\mathrm{RR}=1.01, \mathrm{CI}=0.97-1.06, p=>0.05)$, differentiation $(\mathrm{RR}=3.11, \mathrm{CI}=0.53-18.23, p=0.21)$, stage I $(\mathrm{RR}=0.00, \mathrm{CI}=0.00-1.02, p=0.85)$, stage II $(\mathrm{RR}=0.00, \quad \mathrm{CI}=0.00-3.08, \quad p=0.81)$ and stage III $(\mathrm{RR}=0.00, \mathrm{CI}=0.00-4.46, p=0.83)$ and $\mathrm{PR}$ $(\mathrm{RR}=0.509, \mathrm{CI}=0.046-5.69, p=0.583)$, as summarized in Table 4. The extreme small values of rate ratio and the large confidence intervals from the stage analysis are due to the small number of patients in advanced disease stages (13 in Stage III, and 11 in Stage IV, the reference stage).

\section{Bcl-2 staining}

Of the 185 breast carcinomas examined for Bcl-2 expression, $13(\sim 7.0 \%)$ were negative and $172(\sim 93 \%)$ were positive. One-hundred-twenty-three $(\sim 66.5 \%)$ of the Bcl-2 positive tumors had faint staining and 49 ( 26.5) had strong staining, $43(\sim 23.0 \%)$ were nuclear, $129(\sim 70.0 \%)$ were cytoplasmic, as summarized in Table 2. Figure 1(c) and (d) shows representative sections for strong cytoplasmic and weak nuclear Bcl-2 staining, respectively.

In the paired Spearman rho analysis (Table 3(b)), Bcl-2 expression correlated with stage (0.174), while Bcl-2 pattern correlated with BAG-1 expression $(-0.173)$ and pattern $(-0.174)$, p53 expression $(0.188)$ and intensity $(0.168)$, stage $(0.171)$, differentiation (0.240) and estrogen receptor $(-0.194)$. Bcl2 intensity correlated with that of BAG-1 intensity (0.163).

\section{p53 staining}

Of the 185 patients studied, $43(\sim 23.0 \%)$ had positive p53 staining, $135(\sim 73.0 \%)$ had negative staining and $7(\sim 4.0 \%)$ were missing p53 information (see Table 1$)$. Of the 43 positive cases, $22(\sim 12.0 \%)$ had faint staining and $21(\sim 11.0 \%)$ had strong staining. All cases of p53 positive staining were nuclear, as summarized in Table 2. Figure 1(e) shows representative sections for strong nuclear p53 staining.

Table 3(c) shows the Spearman rho analysis pairing p53 expression and intensity to age, Bcl-2 and BAG-1 expression, pattern, and intensity, tumor type, differentiation, stage, estrogen and progesterone receptors. p53 expression correlated with BAG-1 
Table 4. Predictors of BAG-1

\begin{tabular}{|c|c|c|c|c|}
\hline \multirow[t]{2}{*}{ Factor } & \multicolumn{2}{|l|}{ Univariate } & \multicolumn{2}{|l|}{ Multivariate } \\
\hline & $\mathrm{RR}(95 \% \mathrm{CI})$ & $p$ & $\mathrm{RR}(95 \% \mathrm{CI})$ & $p$ \\
\hline Bcl-2 expression & $3.17(0.90-11.23)$ & 0.07 & $2.48(0.38-15.96)$ & 0.56 \\
\hline Bcl-2 pattern & & & $3.33(0.88-12.67)$ & 0.1 \\
\hline Nuclear & Reference & & & \\
\hline Cytoplasmic & $0.991(0.258-3.814)$ & 0.96 & & \\
\hline Negative & $6.71(1.694-26.26)$ & 0.007 & & \\
\hline Bcl-2 intensity & & & $0.87(0.17-4.34)$ & 0.1 \\
\hline Negative & Reference & & & \\
\hline Weak & $2.568(0.714-9.233)$ & 0.149 & $2.40(0.328-17.63)$ & 0.9 \\
\hline Strong & $6.812(1.297-35.77)$ & 0.023 & $8.924(1.12-70.6)$ & 0.09 \\
\hline p53 & $2.44(0.10-0.60)$ & 0.002 & $0.49(0.16-1.54)$ & 0.21 \\
\hline Differentiation & & & $3.11(0.53-18.23)$ & 0.21 \\
\hline Well & None & & & \\
\hline Moderate & $5.62(1.60-19.60)$ & 0.0068 & & \\
\hline Poor & Reference & & & \\
\hline \multicolumn{5}{|l|}{ Stage } \\
\hline I & $0.003(0.000->100.00)$ & 0.756 & $0.00(0.00-1.02)$ & 0.85 \\
\hline II & $0.001(0.000->100.00)$ & 0.717 & $0.00(0.00-3.08)$ & 0.81 \\
\hline III & $0.001(0.000->100.00)$ & 0.718 & $0.00(0.00-4.46)$ & 0.83 \\
\hline IV & Reference & & & \\
\hline Age & $1.02(0.99-1.06)$ & 0.13 & $1.01(0.97-1.06)$ & $>0.05$ \\
\hline \multicolumn{5}{|l|}{ ER } \\
\hline Negative & Reference & & & \\
\hline Equivalent & $1.997(0.766-5.2)$ & 0.18 & $0.97(0.267-0.353)$ & 0.97 \\
\hline Positive & $9.94(2.66-37.15)$ & 0.001 & $13.26(1.004-175.138)$ & 0.05 \\
\hline \multicolumn{5}{|l|}{ PR } \\
\hline Negative & Reference & & & \\
\hline Equivalent & $1.187(0.298-4.72)$ & 0.808 & $0.678(0.14-4.55)$ & 0.69 \\
\hline Positive & $4.035(0.84-19.3)$ & 0.081 & $0.509(0.046-5.69)$ & 0.583 \\
\hline
\end{tabular}

RR: rate ratio; CI: confidence interval; $p$ : $p$-value; Reference: comparator reference.

expression $(-0.245)$, pattern $(0.247)$ and intensity $(-0.177)$, Bcl-2 pattern (0.168), differentiation (0.359), estrogen $(-0.306)$, and progesterone $(-0.149)$ receptors. p53 intensity correlated with BAG-1 expression $(-0.270)$, pattern $(-0.271)$ and intensity $(-0.195)$, Bcl-2 pattern $(-0.188)$, differentiation (0.369), estrogen $(-0.326)$, and progesterone $(-0.171)$ receptors.

\section{Discussion}

Apoptosis has been increasingly implicated in the pathogenesis, progression and resistance to chemo- therapy and radiation therapy of breast cancer. High level of p53 mutation exists in breast carcinomas [39]. In addition, p53 mutation has been associated with a more aggressive breast cancer phenotype and a worse clinical outcome with increased risk of recurrence and death [40]. p53 mutation has also been linked to resistance to chemotherapy [41], high tumor grade and necrosis, high microvessel density and ipsilateral tumor recurrence [42]. The role of p53 mutation in breast cancer has been reviewed [43, 44]. Similarly, Bcl-2 expression was shown to be associated with favorable clinical outcomes, including ER and PR positivity, low histological grade, well differentiation and sensitivity 
to hormonal therapy, and favorable disease-free and overall survival [45-47]. Furthermore, induction of Bcl-2 by tamoxifen may be involved in the resistance to taxane treatment [48]. The use of Bcl-2 antisense oligonucleotides in the treatment of breast cancer is also under active investigation [49]. Despite the growing number of literature on the value of p53 and Bcl-2 in breast cancer prognosis, there is currently inadequate evidence to support their use in guiding clinical treatment of breast cancer $[26,50,51]$. This is largely due to the inadequate sample size, suboptimal techniques for the determination of p53 and Bcl-2 status and heterogeneity of the patient population used in these studies. Further statistically robust studies are needed to validate their use as prognostic factors in breast cancers, as recommended by the College of American Pathologists consensus statement in 1999 [25]. Our study showing the lack of correlation of Bcl-2 and p53 expression with the disease-free and overall survival of invasive breast carcinomas further illustrates such a requirement.

BAG-1 interacts with Bcl-2 and it is coexpressed with Bcl-2 in response to IL-2 treatment. In addition, BAG-1 expression is upregulated by mutant p53 [52]. It is important to determine if there is a correlation among the expression of BAG-1, p53 and $\mathrm{Bcl}-2$. In addition, it is also interesting to determine if their expressions are correlated with the other prognostic factors such as age, differentiation, ER and PR status and ultimately disease-free and overall survival. Our study represents the first large-scale retrospective clinical study that demonstrated a positive correlation between the expression of BAG-1 and p53. Specifically, p53 expression was correlated to BAG-1 expression $($ rho $=-0.245, p<0.05)$, pattern $($ rho $=0.247$, $p=<0.05)$ and intensity (rho $=-0.177, p<0.05)$. In addition, p53 intensity was correlated with BAG-1 expression (rho $=-0.270, p<0.05)$, pattern $($ rho $=-0.271, p<0.05)$ and intensity $(\mathrm{rho}=-0.195$, $p<0.05)$. Furthermore, p53 expression was associated with histology, estrogen and progesterone receptors, consistent with previous literature. There are conflicting reports in the literature regarding the correlation of expression of BAG-1 and Bcl-2, despite an earlier report that their expression may be coregulated [53]. Although the expression of BAG-1 was found not to correlate with that of Bcl-2 in a panel of 12 breast cancer cell lines [9], a positive correlation of their expression was noted in cell lines by another group [35], and in two cohorts of breast cancer patients $[31,33]$. Our study with a cohort of 185 patients demonstrates that the expression pattern of Bcl-2 correlates with that of BAG- 1 expression $(\mathrm{rho}=-0.173$, $p<0.05$ ), and pattern (rho $=-0.174, p<0.05$ ). In addition, the intensity of Bcl-2 correlates with BAG1 intensity (rho $=0.163, p<0.05$ ) Furthermore, Bcl-2 expression or pattern is associated with stage, better differentiation and positive estrogen receptor, again consistent with previous literature.

We previously reported that the activity of the BAG-1 promoter was upregulated by mutant $\mathrm{p} 53$. We further showed that this upregulation was dosedependent with increasing concentrations of mutant p53 protein [52]. This study represents the first clinical observation of the positive correlation between the expression of BAG-1 and p53. In addition, the expression of p53 was correlated with the intensity and pattern of BAG- 1 expression. Whether mutant p53 increases BAG-1 expression in breast tumors warrants further investigation. p53 has been recognized to play an important role in breast cancer carcinogenesis and resistance to chemotherapy and radiation therapy [1214]. This finding links abnormal cell cycle control and apoptotic machinery in the pathogenesis and possible disease progression of breast cancer. Furthermore, our observations support the further development of targeted therapy in breast cancer, focusing on the cross talk between the different signal transduction pathways. Finally, the coexpression of BAG-1 and p53 observed in clinical sample corroborates the report showing stabilization and cytoplasmic sequestration of wild-type p53 by BAG-1 [54].

BAG-1 also interacts with estrogen and progesterone receptors and influence their transcriptional activation and apoptosis induced by steroid hormones [55-58]. It is equally important to study if a correlation exists between the expression of BAG-1 and estrogen and progesterone receptors. An initial report showed a positive correlation of the two proteins in cell lines [9], although subsequent retrospective clinical studies of breast cancer failed to show such a correlation between the level of nuclear or cytoplasmic BAG-1 protein and the ER or PR positivity using several different monoclonal antibodies [31, 32]. Again, our study demonstrated that a high level of correlation exists between the expression of BAG-1 and estrogen $($ rho $=0.285, p<0.05)$ and progesterone $(\mathrm{rho}=0.182, p<0.05)$ receptors. In addition, there is a correlation between the BAG-1 pattern and the estrogen $(r h o=0.292, p<0.05)$ and progesterone (rho $=0.193, p<0.05$ ) receptors. BAG-1 intensity also correlates with the expression of estrogen receptor 
(rho $=0.331, p<0.05$ ). Our finding is different from our previous report [29], which showed a negative correlation between the expression of BAG-1 and that of estrogen and progesterone receptors in invasive breast carcinoma. This difference is likely due to the higher percentage of ER and PR positive tumors in our current study (44\% ER positive v.s. $35 \%$ positive, and $43 \%$ PR positive v.s. $32 \%$ positive, respectively), lack of missing receptor status in the current study (missing ER $0 \%$ v.s. $37.8 \%$, and missing PR $0 \%$ v.s. 38.7\%, respectively), and the larger sample size (185 patient v.s. 140 patients). Our study confirmed our previous report on the positive correlation between the expression of BAG-1 and the better differentiation of breast carcinoma [29]. Similarly, our study also confirmed our previous report showing the lack of correlation between the expression of BAG-1, age and histology and stage.

Although a high percentage $(86 \%)$ of invasive breast carcinoma in the current study had positive BAG-1 staining, a very low percentage of positive staining was nuclear $(0.5 \%)$, while the majority of the BAG-1 positive tumors stained were cytoplasmic $(85.5 \%)$. We cannot easily explain the low percentage of nuclear BAG-1 expression in this study. The tumor bank material is collected as frozen material and then bisected and processed into either frozen or paraffin blocks. The paraffin block tissue is thus not the same as a standard clinical pathology blocks created directly from fresh tissues. Therefore it is possible that the nuclear BAG-1 signal is compromised in this series for this reason. Nuclear BAG-1 was inversely associated with tumor grade and cytoplasmic BAG-1 was associated with ER status [32]. High grade tumors exhibit weak nuclear BAG-1 expression. Distribution of tumor grade between our previous and current studies is dissimilar; in our current study $58 \%$ of the tumors are poorly differentiated, whereas in our previous study $20.7 \%$ were poorly differentiated. The presence of a high percentage of poorly differentiated tumors may explain the low percentage of nuclear BAG-1 expression in our current study. Cytoplasmic BAG-1 expression, therefore, does not seem to be associated with disease-free or overall survival in breast cancer patients with all stages included, consistent with previous reports [29, 33], although its expression may be associated with a better clinical outcome in patients with early stage breast cancer [31]. Our current study could not verify our previous finding of the association between nuclear BAG-1 expression and poor prognosis (result not shown), since this study had only one case $(0.5 \%)$ with positive nuclear BAG-1 staining, while our previous study had 26 cases (18.2\%). Although this study has a larger cohort, there are only 25 patients whose tumor is negative for BAG-1, which may limit the power of multivariate analysis for the correlation study, the disease-free and overall survival analysis. Since our patient population included patients with all stages, the favorable clinical outcome was not detected in our current study. Although it may be interesting to perform subgroup analysis in patients with early stage breast cancer only, the power of the study to detect any real difference would be quite low, as demonstrated recently by the failure to detect any association between the expression of BAG-1 and survival in a cohort of breast cancer patients with all stages included [33].

Our study with a cohort of 185 breast cancer patients shows that the expression of BAG-1 correlates with that of Bcl-2, p53, differentiation, ER and PR, all of which are important molecules of breast cancer oncogenesis. Our finding is consistent with the ample preclinical data demonstrating the interaction of BAG1 with Bcl-2, p53, ER and PR. Abnormal expression of BAG-1 is likely an important factor in the pathogenesis and progression in breast cancer because of its involvement in cellular growth signal transduction, apoptosis, cell cycle control, response to hormonal regulation and gene transcription. It would be interesting to study the roles of each BAG-1 isoform in these pathways and design therapeutic strategies to target BAG-1-mediated processes in the treatment of breast cancer.

\section{Acknowledgements}

We thank the Canadian Institutes of Health Research, the National Cancer Institute of Canada and the University of Miami Sylvester Comprehensive Cancer Center for their grants and support for this project.

\section{References}

1. Bardelli A, Longati P, Albero D, Goruppi S, Schneider C, Ponzetto C, Comoglio PM: HGF receptor associates with the anti-apoptotic protein BAG-1 and prevents cell death. Embo J 15: 6205-6212, 1996

2. Takayama S, Sato T, Krajewski S, Kochel K, Irie S, Millan JA, Reed JC: Cloning and functional analysis of BAG-1: a novel Bcl-2-binding protein with anti-cell death activity. Cell 80: 279-284, 1995 
3. Takayama S, Bimston DN, Matsuzawa S, Freeman BC, AimeSempe C, Xie Z, Morimoto RI, Reed JC: BAG-1 modulates the chaperone activity of Hsp70/Hsc70. Embo J 16: 4887-4896, 1997

4. Zeiner M, Niyaz Y, Gehring U: The hsp70-associating protein Hap46 binds to DNA and stimulates transcription. Proc Natl Acad Sci USA 96: 10194-10199, 1999

5. Wang HG, Takayama S, Rapp UR, Reed JC: Bcl-2 interacting protein, BAG-1, binds to and activates the kinase Raf-1. Proc Natl Acad Sci USA 93: 7063-7068, 1996

6. Zeiner M, Gehring U: A protein that interacts with members of the nuclear hormone receptor family: identification and cDNA cloning. Proc Natl Acad Sci USA 92: 11465-11469, 1995

7. Tang SC: BAG-1, an anti-apoptotic tumour marker. IUBMB Life 53: 99-105, 2002

8. Takayama S, Krajewski S, Krajewska M, Kitada S, Zapata JM, Kochel K, Knee D, Scudiero D, Tudor G, Miller GJ, Miyashita T, Yamada M, Reed JC: Expression and location of Hsp70/Hsc-binding anti-apoptotic protein BAG-1 and its variants in normal tissues and tumor cell lines. Cancer Res 58: 3116-3131, 1998

9. Brimmell M, Burns JS, Munson P, McDonald L, O'Hare MJ, Lakhani SR, Packham G: High level expression of differentially localized BAG-1 isoforms in some oestrogen receptorpositive human breast cancers. Br J Cancer 81: 1042-1051, 1999

10. Luders J, Demand J, Papp O, Hohfeld J: Distinct isoforms of the cofactor BAG-1 differentially affect Hsc70 chaperone function. J Biol Chem 275: 14817-14823, 2000

11. Chen J, Xiong J, Liu H, Chernenko G, Tang SC: Distinct BAG-1 isoforms have different anti-apoptotic functions in BAG-1-transfected C33A human cervical carcinoma cell line. Oncogene 21: 7050-7059, 2002

12. Linn SC, Honkoop AH, Hoekman K, van der Valk P, Pinedo HM, Giaccone G: p53 and P-glycoprotein are often coexpressed and are associated with poor prognosis in breast cancer. Br J Cancer 74: 63-68, 1996

13. Aas T, Borresen AL, Geisler S, Smith-Sorensen B, Johnsen H, Varhaug JE, Akslen LA, Lonning PE: Specific P53 mutations are associated with de novo resistance to doxorubicin in breast cancer patients. Natl Med 2: 811-814, 1996

14. Degeorges A, de Roquancourt A, Extra JM, Espie M, Bourstyn E, de Cremoux P, Soussi T, Marty M: Is p53 a protein that predicts the response to chemotherapy in node negative breast cancer? Breast Cancer Res Treat 47: 47-55, 1998

15. Hori M, Nogami T, Itabashi M, Yoshimi F, Ono H, Koizumi $\mathrm{S}$ : Expression of Bcl-2 in human breast cancer: correlation between hormone receptor status, p53 protein accumulation and DNA strand breaks associated with apoptosis. Pathol Int 47: 757-762, 1997

16. Elledge RM, Green S, Howes L, Clark GM, Berardo M, Allred DC, Pugh R, Coca D, Ravdin P, O’Sullivan J, Rivkin S, Martino S, Osborne CK: bcl-2, p53, and response to tamoxifen in estrogen receptor-positive metastatic breast cancer: a Southwest Oncology Group study. J Clin Oncol 15: 1916-1922, 1997

17. Kapranos N, Karaiosifidi H, Valavanis C, Kouri E, Vasilaros $\mathrm{S}$ : Prognostic significance of apoptosis related proteins $\mathrm{Bcl}-2$ and Bax in node-negative breast cancer patients. Anticancer Res 17: 2499-2505, 1997

18. Kobayashi S, Iwase H, Ito Y, Yamashita H, Iwata H, Yamashita T, Ito K, Toyama T, Nakamura T, Masaoka A: Clinical significance of bcl-2 gene expression in human breast cancer tissues. Breast Cancer Res Treat 42: 173-181, 1997
19. Berardo MD, Elledge RM, de Moor C, Clark GM, Osborne CK, Allred DC: bcl-2 and apoptosis in lymph node positive breast carcinoma. Cancer 82: 1296-1302, 1998

20. Papadimitriou CS, Costopoulos JS, Christoforidou BP, Kotsianti AJ, Karkavelas GS, Hytiroglou PM, Koufogiannis DJ, Nenopoulou HE: Expression of Bcl-2 protein in human primary breast carcinomas and its correlation with multifocality, histopathological types and prognosis. Eur J Cancer 33: 1275-1280, 1997

21. Sierra A, Lloveras B, Castellsague X, Moreno L, GarciaRamirez M, Fabra A: Bcl-2 expression is associated with lymph node metastasis in human ductal breast carcinoma. Int J Cancer 60: 54-60, 1995

22. Gorczyca W, Markiewski M, Kram A, Tuziak T, Domagala $\mathrm{W}$ : Immunohistochemical analysis of bcl-2 and p53 expression in breast carcinomas: their correlation with Ki-67 growth fraction. Virchows Arch 426: 229-233, 1995

23. Olopade OI, Adeyanju MO, Safa AR, Hagos F, Mick R, Thompson CB, Recant WM: Overexpression of BCL-x protein in primary breast cancer is associated with high tumor grade and nodal metastases. Cancer J Sci Am 3: 230-237, 1997

24. Krajewski S, Blomqvist C, Franssila K, Krajewska M, Wasenius VM, Niskanen E, Nordling S, Reed JC: Reduced expression of proapoptotic gene BAX is associated with poor response rates to combination chemotherapy and shorter survival in women with metastatic breast adenocarcinoma. Cancer Res 55: 4471-4478, 1995

25. Fitzgibbons PL, Page DL, Weaver D, Thor AD, Allred DC, Clark GM, Ruby SG, O’Malley F, Simpson JF, Connolly JL, Hayes DF, Edge SB, Lichter A, Schnitt SJ: Prognostic factors in breast cancer. College of American Pathologists Consensus Statement 1999. Arch Pathol Lab Med 124: 966-978, 2000

26. Hamilton A, Piccart M: The contribution of molecular markers to the prediction of response in the treatment of breast cancer: a review of the literature on HER-2, p53 and BCL-2. Ann Oncol 11: 647-663, 2000

27. Yang X, Hao Y, Ding Z, Pater A, Tang SC: Differential expression of antiapoptotic gene BAG-1 in human breast normal and cancer cell lines and tissues. Clin Cancer Res 5: 1816-1822, 1999

28. Kudoh M, Knee DA, Takayama S, Reed JC: Bag1 proteins regulate growth and survival of ZR-75-1 human breast cancer cells. Cancer Res 62: 1904-1909, 2002

29. Tang SC, Shehata N, Chernenko G, Khalifa M, Wang X, Shaheta N: Expression of BAG-1 in invasive breast carcinomas. J Clin Oncol 17: 1710-1719, 1999

30. Yamauchi H, Adachi M, Sakata K, Hareyama M, Satoh M, Himi T, Takayama S, Reed JC, Imai K: Nuclear BAG-1 localization and the risk of recurrence after radiation therapy in laryngeal carcinomas. Cancer Lett 165: 103-110, 2001

31. Turner BC, Krajewski S, Krajewska M, Takayama S, Gumbs AA, Carter D, Rebbeck TR, Haffty BG, Reed JC: BAG-1: a novel biomarker predicting long-term survival in early-stage breast cancer. J Clin Oncol 19: 992-1000, 2001

32. Townsend PA, Dublin E, Hart IR, Kao RH, Hanby AM, Cutress RI, Poulsom R, Ryder K, Barnes DM, Packham $\mathrm{G}$ : BAG-i expression in human breast cancer: interrelationship between BAG-1 RNA, protein, HSC70 expression and clinico-pathological data. J Pathol 197: 51-59, 2002

33. Sjostrom J, Blomqvist C, von Boguslawski K, Bengtsson NO, Mjaaland I, Malmstrom P, Ostenstadt B, Wist E, Valvere V, Takayama S, Reed JC, Saksela E: The predictive value of bcl- 
2, bax, bcl-xL, bag-1, fas, and fasL for chemotherapy response in advanced breast cancer. Clin Cancer Res 8: 811-816, 2002

34. Adachi M, Torigoe T, Takayama S, Imai K: BAG-1 and Bcl-2 in IL-2 signaling. Leuk Lymphoma 30: 483-491, 1998

35. Zapata JM, Krajewska M, Krajewski S, Huang RP, Takayama S, Wang HG, Adamson E, Reed JC: Expression of multiple apoptosis-regulatory genes in human breast cancer cell lines and primary tumors. Breast Cancer Res Treat 47: 129-140, 1998

36. Watson PH, Snell L, Parisien M: The NCIC-Manitoba Breast Tumor Bank: a resource for applied cancer research. Cmaj 155: 281-283, 1996

37. Hiller T, Snell L, Watson PH: Microdissection RT-PCR analysis of gene expression in pathologically defined frozen tissue sections. Biotechniques 21: 38-40, 42, 44, 1996

38. Rorke S, Murphy S, Khalifa M, Chernenko G, Tang SC: Prognostic significance of BAG-1 expression in nonsmall cell lung cancer. Int J Cancer 95: 317-322, 2001

39. Barnes DM, Camplejohn RS: P53, apoptosis, and breast cancer. J Mammary Gland Biol Neoplasia 1: 163-175, 1996

40. Elledge RM, Allred DC: Prognostic and predictive value of p53 and p21 in breast cancer. Breast Cancer Res Treat 52: 79-98, 1998

41. Ferreira CG, Tolis C, Giaccone G: p53 and chemosensitivity. Ann Oncol 10: 1011-1021, 1999

42. Hieken TJ, Farolan M, D'Alessandro S, Velasco JM: Predicting the biologic behavior of ductal carcinoma in situ: an analysis of molecular markers. Surgery 130: 593-600; discussion 591-600, 2001

43. Lindahl T, Engel G, Ahlgren J, Klaar S, Bjohle J, Lindman H, Andersson J, von Schoultz E, Bergh J: Can axillary dissection be avoided by improved molecular biological diagnosis? Acta Oncol 39: 319-326, 2000

44. Phillips HA: The role of the p53 tumour suppressor gene in human breast cancer. Clin Oncol (R Coll Radiol) 11: 148-155, 1999

45. Ciocca DR, and Elledge, R: Molecular markers for predicting response to tamoxifen in breast cancer patients. Endocrine 13: 1-10, 2000

46. Schorr K, Li M, Krajewski S, Reed JC, Furth PA: Bcl-2 gene family and related proteins in mammary gland involution and breast cancer. J Mammary Gland Biol Neoplasia 4: 153-164, 1999

47. Daidone MG, Luisi A, Veneroni S, Benini E, Silvestrini R: Clinical studies of Bcl-2 and treatment benefit in breast cancer patients. Endocr Relat Cancer 6: 61-68, 1999
48. Kim R, Osaki A, Toge T: A pitfall in the survival benefit of adjuvant chemotherapy for node-and hormone receptorpositive patients with breast cancer: the paradoxical role of Bcl-2 oncoprotein (review). Int J Oncol 19: 1075-1080, 2001

49. Tolcher AW: Novel compounds in the therapy of breast cancer: opportunities for integration with docetaxel. Oncologist 6(Suppl 3): 40-44, 2001

50. Ravaioli A, Bagli L, Zucchini A, Monti F: Prognosis and prediction of response in breast cancer: the current role of the main biological markers. Cell Proliferat 31: 113-126, 1998

51. Bergh J: Clinical studies of p53 in treatment and benefit of breast cancer patients. Endocr Relat Cancer 6: 51-59, 1999

52. Yang X, Pater A, Tang SC: Cloning and characterization of the human BAG-1 gene promoter: upregulation by tumor-derived p53 mutants. Oncogene 18: 4546-4553, 1999

53. Adachi M, Sekiya M, Torigoe T, Takayama S, Reed JC, Miyazaki T, Minami Y, Taniguchi T, Imai K: Interleukin-2 (IL-2) upregulates BAG-1 gene expression through serinerich region within $\mathrm{IL}-2$ receptor beta c chain. Blood 88 : 4118-4123, 1996

54. King FW, Wawrzynow A, Hohfeld J, Zylicz M: Cochaperones Bag-1, Hop and Hsp40 regulate Hsc70 and Hsp90 interactions with wild-type or mutant p53. Embo J 20: 62976305,2001

55. Kullmann M, Schneikert J, Moll J, Heck S, Zeiner M, Gehring $\mathrm{U}$, Cato AC: RAP46 is a negative regulator of glucocorticoid receptor action and hormone-induced apoptosis. J Biol Chem 273: 14620-14625, 1998

56. Liu R, Takayama S, Zheng Y, Froesch B, Chen GQ, Zhang X, Reed JC, Zhang XK: Interaction of BAG-1 with retinoic acid receptor and its inhibition of retinoic acid-induced apoptosis in cancer cells. J Biol Chem 273: 16985-16992, 1998

57. Froesch BA, Takayama S, Reed JC: BAG-1L protein enhances androgen receptor function. J Biol Chem 273: 11660-11666, 1998

58. Yang X, Chernenko G, Hao Y, Ding Z, Pater MM, Pater A, Tang SC: Human BAG-1/RAP46 protein is generated as four isoforms by alternative translation initiation and overexpressed in cancer cells. Oncogene 17: 981-989, 1998

Address for offprints and correspondence: Dr Shou-Ching Tang, $\mathrm{MD}, \mathrm{PhD}$, Sylvester Comprehensive Cancer Center, University of Miami, 1550 NW 10th Avenue, Papanicolaou Building, Room 109, Miami, FL 33136, USA; Tel.: +1-305-243-6554; Fax: +1-305-2435239; E-mail: stang@med.miami.edu 